\title{
Influence of NAFDAC Mobile Drugs Authentication Service on the Use of Fake Drugs Among Consumers in Southeast Nigeria
}

\author{
Joseph Oluchukwu Wogu ${ }^{1}$, Lois Nnenna Omaka-Amari ${ }^{2}$, Uchenna Cosmas Ugwu ${ }^{3}$, \\ Joel Chinedum Ugwuoke $^{1} \&$ Michael Anene Agu $^{2}$ \\ ${ }^{1}$ Department of Mass Communication, University of Nigeria Nsukka, P.M.B. 410001, Enugu State, Nigeria \\ ${ }^{2}$ Department of Human Kinetics and Health Education, Ebonyi State University, Abakaliki P.M.B. 53, Ebonyi \\ State, Nigeria \\ ${ }^{3}$ Department of Human Kinetics and Health Education, University of Nigeria Nsukka, P.M.B. 410001, Enugu \\ State, Nigeria \\ Correspondence: Uchenna Cosmas Ugwu, Department of Human Kinetics and Health Education, University of \\ Nigeria Nsukka, P.M.B. 410001, Enugu State, Nigeria. Tel: 234-803-778-6068. E-mail: \\ uchennacos.ugwu@unn.edu.ng
}

Received: February 11, 2019 Accepted: April 7, 2019 Online Published: April 8, 2019

doi:10.5539/gjhs.v11n5p87 URL: https://doi.org/10.5539/gjhs.v11n5p87

\begin{abstract}
Objective: This paper investigates the influence of Mobile Authentication Service (MAS) in eliminating the consumption of fake/counterfeit drugs in South-east Nigeria.

Methods: 1000 respondents were randomly selected in the five states of the South-east as study sample, while a structured questionnaire was used for collecting data. SPSS version 20.0 was used to analyse the data.

Results: Analysis results reveal that there is a low level of MAS scheme awareness while few persons operate the MAS scheme. It further reveals that MAS scheme made no impact on the distribution and consumption of fake/counterfeit drugs. It also reveals people's inability to procure appropriate phone technology, poor network services, and low level of MAS scheme media awareness campaign was responsible for MAS scheme ineffectiveness.

Conclusion: NAFDAC MAS scheme has not reduced or eliminated the production, distribution and consumption of fake/counterfeit drugs in the South-east Nigeria. This is because of inappropriate media awareness campaign, people's inability to procure the appropriate phone technology and access good network services required to operate the MAS scheme. This paper recommends appropriate massive media awareness campaign on the MAS Scheme, modernisation of MAS scheme software to accommodate lower level of phone technology, and improved network access as panacea for MAS scheme effectiveness.
\end{abstract}

Keywords: fake/counterfeit, drugs, MAS scheme, phone technology, and awareness

\section{Introduction}

The manufacturing, distribution and consumption of fake drugs or counterfeit medications in South-east Nigeria is perverse and has led to many adverse health problems such as injury, disability, paralysis, complications and treatment failure, and even death in some instances (Akinyandenu, 2013; Foreman, 2014; Iwokwagh, 2013; IMPACT, 2013). For instance, "the intake of counterfeit anti-malaria drugs alone takes the lives of more than 700,000 Africans yearly' (NAFDAC News, 2013:11). Scholars like Osibo (1998) and Bamitale (2013) observed that there are more fake or counterfeit drugs than genuine drugs in circulation in Nigeria. Lambo (2006) reported that $54 \%$ of drugs in every major pharmacy in Lagos were fake in 1990, and that the figure rose to $80 \%$ in the subsequent year. Fake or counterfeit drugs as used here refers to pharmaceutical products that deceptively represent their origin, authenticity or effectiveness (Ukaoha, Dim, Odikayor-Ogbomo, \& Daodu, 2015; Wertheimer \& Wang, 2012). Their components differ from the original and are incorrect or harmful ingredients. Akunyili (2010: 17-18) comprehensively defined it as that drug "which appears to be what it is not or drug product that does not measure up to the required quality standards, or drug whose approved time limit for the expected performance of the active ingredients has expired". 
The Federal Government promulgated the counterfeit and fake drugs (miscellaneous provisions) Decree No. 21 of 1988, which prohibited the sale and distribution of counterfeit, adulterated, banned, and fake drugs. The weaknesses of the decree led to the emergence of Decree No.21 of 1989 and other subsequent amendments (Akunyili, 2013) that culminated in the establishment of the National Agency for Foods and Drugs Administration and Control (NAFDAC) by Decree No. 15 of 1993. Primarily, NAFDAC was fully responsible for regulating and controlling the manufacture, importation, exportation, advertisement, distribution, sale and use of food, drugs, cosmetics, medical devices, chemicals and packaged water in Nigeria (Akunyili, 2005). These products have high records of fakes in circulation across the country and beyond.

NAFDAC adopted enlightenment campaign programmes in the form of jingles, fliers, leaflets, posters, billboards, workshops, and seminars to combat counterfeit drug consumption. However, these strategies failed due to many problems such as limited access of the media to the populace. Thus, NAFDAC adopted Mobile application services, which posses easier and wide access, as instrument for fighting the use of fake drugs in Nigeria. A mobile application refers to a software application that can be run on a mobile platform using phone or web page (Wigmore, 2013). With the application, customers check if the drugs they want to purchase are genuine typing-in a single-use alphanumeric character contained on the drug packaging to a designated server (Zeppa \& Lewis, 2013). In a response time of 30 seconds or less, a network reply of "genuine" or "fake" will follow. This Drug Checker Mobile Authenticating service is designed for use on Android-based phones and other smart phones. This is called NAFDAC Mobile Authentication Service (MAS) using Short Message Service (SMS).

All goods approved by NAFDAC are to be covered under the MAS service scheme particularly antibiotics, anti-inflammatory and anti-malarial pharmaceutical products. Four MAS Service Providers and their Short Codes as approved are: PharmaSecure (code: 38351); Sproxil (Code: 38353); Savanté (Code: 38120); UBQ-t/Kezzler (Code: 20966); and M-Pedigree (Code: 1393). Any of these service providers can be used by consumers provided: i) Theyscratch the product's pin and send it as text message at the point of purchase. ii) They text the right pin to the right code of the provider they want to use. iii) They buy drugs from only registered pharmacies and patent medicines shops. iv) They obtained and retain receipts of payment for items purchased in case there is a problem. v) They report all cases of counterfeit products to NAFDAC's anti-counterfeit desk in Pharmaco-vigilance and Post Marketing Surveillance Directorate, and report other complaints relating to the scheme through a free text message to the PRASCOR number - 20543. This paper aims to investigate the extent of public utilisation of MAS service scheme and its influence on the control and eradication of the consumption of counterfeit drugs in South-east Nigeria.

\subsection{Fake/Counterfeit Drugs}

The definition of fake or counterfeit drugs differ from country to country (World Health Organisation, 2013) although WHO Member States seem to share similar definition. They emphasize deliberate and fraudulent mislabelling of drugs with respect to brand and generic products as the defining indices of fake drugs. In this sense, counterfeit products include products with correct or wrong ingredients, with or without active ingredients, inadequate quantities of ingredient(s), and with fake packaging. Nigeria's Counterfeit and Fake Drugs and Unwholesome Processed Foods (Miscellaneous Provisions) Decree (1999) defines fake and counterfeit drugs as:

a) any product which is not what it purports to be: b) or any drug or drug product which is coloured, coated, powdered or polished that the damage is concealed or which is made to appear to be better or of greater therapeutic value than it really is, which is not labelled in the prescribed manner or which label or containers or anything accompanying the drug bears any statement, design or device which makes a false claim for the drug or which is false or misleading; or c) any drug or drug product whose container is so made, formed or filled as to be misleading; or d) any drug product whose label does not bear adequate direction for use and such adequate warning against use in those pathological conditions or by children where its use may be dangerous to health or against unsafe usage or methods or duration of use; or e) any drug product which is not registered by the agency in accordance with the provisions of the Food, Drugs and Related Products Decree 1993, as amended.

Similarly, Agbaraji and Ezeh (2012) defined counterfeited drugs as those drugs that are not fake and have been manufactured using inaccurate quantities, or inaccurate ingredients, to either lessen the potency, or quash the potency of drugs altogether, and the same is applicable to food counterfeit. Therefore, counterfeit or fake drugs simply refer to drugs that are produced and sold in forms that deceptively represent their origin, contents and authenticity or effectiveness.

\subsection{Communication, Technology and Anti Fake Drugs Campaign}

There is sufficient empirical evidence that counterfeit drugs are inimical to human existence and that governments 
at all levels of the society across the world have been waging wars against their production, distribution and consumption. Predominantly, television, newspapers, radio stations, etc were earlier used to project commercials, public alert notices on banned products, phone-in programmes, talk shows, etc (Akunyili, 2005; Dike,Onah, and Onwuka, 2014). However, these instruments do not allow for mass input or response to whatever they hear or experience. Importantly, they only describe fake drugs but have no mechanism for identifying them individually in different medical shops to deter consumers from buying them.

Thus, the World Economic Forum (2010) advocated for the use of the New Media Technologies (NMTs), which are powerful forces for change and a fundamentally important way to create awareness, motivate and engage individuals in pro-health behaviours. In the words of Hauser (1998:86) the New Media provides the 'discursive space in which individuals and groups congregate to discuss matters of mutual interest and, where possible, to reach a common judgement'. Etzo and Collender (2010) recorded that Celtel and AIDS Information Centre effectively employed this in Uganda to create AIDS awareness to 15000 mobile phone subscribers. Similarly, OurMed (2015) records that Ghana introduced mPedigree - a GSM network scheme in 2007 to provide pharmaceutical consumers and patients with the means to verify if the medicines they want to purchase are original through a free two-way SMS message. India initiated a similar service scheme as instrument for managing the phenomenal growth of her pharmaceutical industry as well as suppressing the counterfeit drug market (Chandu, 2011).

Similarly, Iwokwagh (2013) noted that NAFDAC introduced a range of fake drugs detecting technologies such as Truscan, Mobile Authentication Service (MAS), using Short Message Service (SMS), Black eye, and Radio Frequency Identification (RFID) to assist NAFDAC then detect and stop fake and counterfeit drugs. Among these, NAFDAC introduced a Mobile Authentication Service (MAS) in 2010 to enable consumers check whether a drug is original or fake with the aid of mobile phone using Sproxil technology. Sproxil is a venture-backed, social enterprise that provides world-class brand protection services in emerging markets (Sproxil, 2015).The Mobile Authentication Service (MAS) programme uses Short Message Service (SMS) to create mass awareness, and provide for on the spot verification of suspected counterfeit products (NAFDAC News, 2013).

In the MAS scheme, SMS and USSD are the means of interaction through the Sproxil technology irrespective of phone capacity and data availability i.e. it does not consume the user's available data. However, the scheme was designed at a time when internet penetration was very lower than it is now. This is the reason why only rich or high level mobile applications that have unlimited access to the scheme now than others. Little or no empirical research evaluated the potency of this service in reducing the distribution and consumption of counterfeit drugs particularly in the South-east. This paper is an attempt to fill this gap.

\subsection{Research Question}

In pursuit of the goals of this paper, the following questions guide the inquiry:

a. Is there a high level of awareness and use of MAS scheme by drug consumers in the South-east Nigeria?

b. Has the introduction and use of MAS scheme reduced the distribution and consumption of counterfeit drugs in South-east Nigeria?

c. What are the major limitations of the use and effect of MAS scheme as instrument for eradicating counterfeit drugs in South-east Nigeria?

\subsection{Significance of the Study}

The study will enable NAFDAC and other anti-drug agencies in Nigeria to evaluate the impact of the MAS scheme policy and problems confronting its implementation. The recommendations offered by the paper shall enable these bodies review and modernise the mechanisms of MAS scheme operation to enhance its effectiveness. The study shall equally highlight the potency and the need for the use of mobile applications in social marketing communications and anticrime campaigns. The study equally explicates the role of ICT in re-engineering behaviour modification and social change in South-east Nigeria.

\subsection{Framework of Analysis}

This study adopts the ACADA model or framework of analysis as espoused by the United Nations Children Fund (UNICEF). The framework holds that for any development or social change or behaviour modification to occur, there must be advocacy, social mobilization, and programme communications (UNICEF, 2000). People's acceptance of change leads to development. The framework emphasizes thorough, practical and sustained approach to the evolution, design and delivery of social change campaigns. Thus, advocacy, social mobilization, and programme communications enable people to accept change. The primary goal of ACADA model/framework 
of analysis is behavioural change, and the processes that lead to it. This framework enables the researchers to investigate the MAS scheme as instrument of change or strategy adapted to effect people's behaviour modification in matters of distributing and consuming counterfeit drugs in the South-east. It highlights MAS as important variable for study and a dependent variable that shapes or alters the pattern of counterfeit drugs consumption. It enables the researchers concentrate on the impact of MAS on drug consumers' behaviour.

\section{Methods}

The study was restricted in geographical scope to the South-east Nigeria, and thematically to the application or use of MAS scheme to detect counterfeit drugs. Periodically, the study is restricted from 2010 (when the MAS scheme was introduced by NAFDAC) to 2017, which is the period of inquiry.

This paper adopts a cross-sectional survey of the five states of the South-east Nigeria. Considering their enormous landmass and population of people, the capitals of these states, i.e. Abakiliki, Awka, Enugu, Owerri, and Umuahia are selected as the areas of study. A structured questionnaire in five-point Likert scale format was used to generate data from a sample of 1000 respondents randomly selected from registered pharmacists and patent medicine shops, and their customers in the various state capitals of the South-east. Two hundred questionnaires were distributed in each of the five study areas. To complement the primary data, the researchers consulted published books, journals, conference and workshop papers, newspapers, magazines, and government gazettes as can be found in public and private libraries, and the internet for secondary data. Experts in the Faculties of Social Sciences and Arts, University of Nigeria who were asked to assess the relevance of the contents and tools used, and to ensure their potency, tested the validity of the instrument used. On the other hand, a test-retest method was carried out within an interval of two weeks in the capital Rivers state to test its reliability. An analysis of the reliability coefficient of the research instrument was estimated to be 0.954 using Cronbach's Alpha technique. The data generated during the research was analyzed using percentage and analysis of variance (ANOVA) (with SPSS, version 20.0 package).

\section{Results}

An analysis of the demographic data of respondents reveals that 444 respondents out of 1000 (i.e. $44.9 \%$ ) are males while 556 respondents representing $55.1 \%$ are females. Thus, the inquiry is gender sensitive, while the inferences drawn are gender inclusive. Further, 312 respondents representing $31.2 \%$ falls within the age bracket of $18-28$ years, 403 respondents representing $40.3 \%$ falls within $29-38$ years, 188 respondents representing $18.8 \%$ are between the ages of 39 and 48 years, while 97 respondents representing 9.7\% are 49 years and above. This statistics shows that respondents to this study are people that have acquired relevant technology and knowledge to apply or participate in the MAS scheme. Educationally, 899 respondents (i.e. 89.9\%) are graduates of one tertiary institution or the other, while 101 respondents representing $10.1 \%$ are high school graduates. Therefore, none of the respondents is handicapped from participating in the MAS scheme.

The SPSS univariate analysis of responses to questions that interrogated if there were high-level awareness of NAFDAC MAS scheme by drug consumers in the South-east Nigeria reveals a total grand mean of 2.23 with a standard error of .053 and a standard deviation of .762. Its Tests of Between-Subjects Effects reveal that the confidence interval of the responses lies between 2.183and 2.273, which is within the $95 \%$ confidence interval of the difference. In addition, it reveals that the mean differences of the entire responses shows a significant difference $(P=.000)$. Further analysis of the respondents' regular use of the NAFDAC MAS scheme to detect and report the sale of counterfeit drugs while purchasing drugs reveals a total grand mean of 2.23 with a standard error of .056, and a standard deviation of .808. Its Tests of Between-Subjects Effects reveals that the confidence interval of the responses lies between 2.178 and 2.276. In addition, it reveals that the mean differences of the entire responses shows a significant difference $(P=.000)$.

The SPSS univariate analysis of responses to the question that investigated if the NAFDAC MAS scheme reduced the distribution, sale, and consumption of fake/counterfeit drugs in the South-east in Nigeria reveals a total grand mean of 2.20 with a standard error of .023 and a standard deviation of .716. Its Tests of Between-Subjects Effects reveals that the confidence interval of the responses lies between 2.157 and 2.245. In addition, it reveals that the mean differences of the entire responses shows a significant difference $(P=.006)$.

The univariate analysis of responses to the statement that lack of Will to use the MAS scheme is responsible for MAS failure to reduce or eliminate the production, distribution and consumption of fake/counterfeit drugs in the South-east Nigeria reveals a total grand mean of 2.23 with a standard error of .052, and a standard deviation of .762. Its Tests of Between-Subjects Effects reveals that the confidence interval of the responses lies between 2.183 and 2.273. In addition, it reveals that the mean differences of the entire responses shows a significant difference $(P$ $=.000)$. 
The analysis of responses to the statement that people's inability to procure efficient phone technology and poor network services contributed to MAS scheme inability to reduce or eliminate the production, distribution and consumption of fake/counterfeit drugs in the South-east in Nigeria reveals a total grand mean of 4.04 with a standard error of .038, and a standard deviation of 1.264. Its Tests of Between-Subjects Effects reveal that the confidence interval of the responses lies between 3.969 and 4.119. In addition, it reveals that the mean differences of the entire responses shows a significant difference $(P=.000)$.

Further analysis of responses to the statement that low level of MAS media awareness campaign contributed to MAS scheme inability to reduce or eliminate the production, distribution and consumption of fake/counterfeit drugs in the South-east Nigeria reveals a total grand mean of 4.21 with a standard error of .071, and a standard deviation of 1.063.Its Tests of Between-Subjects Effects reveals that the confidence interval of the responses lies between 4.152 and 4.276. In addition, it reveals that the mean differences of the entire responses shows a significant difference $(P=.000)$.

\section{Discussion}

This paper studied the impact of MAS scheme on the eradication of fake/counterfeit drug distribution and consumption in South-east Nigeria. In furtherance of this objective, the paper investigated the level of people's awareness of NAFDAC MAS scheme in the South-east Nigeria. Findings showed that the majority of the respondents are not aware of NAFDAC MAS scheme. Further analysis of their responses on their regular use of the NAFDAC MAS scheme to detect and report the sale of counterfeit drugs while purchasing drugs also reveals that the majority of the respondents do not use the NAFDAC MAS scheme when purchasing drugs to detect fake/counterfeit drugs.

An analysis of responses to the statement that the NAFDAC MAS scheme reduced the distribution, sale, and consumption of fake/counterfeit drugs in the South-east Nigeria reveals that MAS scheme has not reduced the distribution, sale, and consumption of fake/counterfeit drugs in the South-east Nigeria. Attempt to find out the factors that are responsible for MAS scheme inability to reduce the distribution, sale, and consumption of fake/counterfeit drugs in the Southeast Nigeria reveals that lack of will to use the MAS scheme has no impact. Thus, lack of will to use the MAS scheme did not contribute to its inability to reduce the distribution, sale, and consumption of fake/counterfeit drugs in the South-east Nigeria.

However, one of the results of the analysis reveals that people's inability to procure efficient phone technology and poor network services contributed to MAS scheme inability to reduce or eliminate the production, distribution and consumption of fake/counterfeit drugs in the South-east Nigeria. This implies that people's inability to procure efficient phone technology and poor network services required to operate the MAS scheme contributed to its inability to reduce or eliminate the production, distribution and consumption of fake/counterfeit drugs in the South-east Nigeria. Further analysis of responses to the statement that low level of MAS media awareness campaign contributed to low application and the inability of MAS scheme to reduce or eliminate the production, distribution and consumption of fake/counterfeit drugs in the South-east Nigeria reveals that low level of MAS media awareness campaign contributed to low application and the inability of MAS scheme to reduce or eliminate the production, distribution and consumption of fake/counterfeit drugs in the South-east Nigeria.

\section{Conclusions and Recommendations}

This research evaluated the impact of NAFDAC MAS scheme on the production, distribution and consumption of fake/counterfeit drugs in the South-east Nigeria. After due consideration of these findings, this paper concludes that NAFDAC MAS scheme has not reduced or eliminated the production, distribution and consumption of fake/counterfeit drugs in the South-east Nigeria. This is because of inappropriate media awareness campaign, people's inability to procure the appropriate phone technology and access good network services required to operate the MAS scheme. This paper, therefore, recommends appropriate massive media awareness campaign on the introduction, mechanism, and importance of MAS Scheme. The software for the operation of MAS scheme should be modified to accommodate wider and lower level of phone technology. Network providers should extend or establish their reception masks across the country to improve their access. These will improve the efficaciousness of MAS scheme in eliminating fake drugs production, distribution and consumption in South-east Nigeria.

\section{Ethics Approval and Consent to Participate}

Appropriate Ethics approval and Consent of the respondents to participate in the research were obtained after detailed explanation of the intent of the research, guarantee of individual anonymity were given. We hereby authorise and consent to the publication of this paper if accepted. 


\section{Funding}

None.

\section{Authors' Contributions}

Authors contributed equally in all aspect of this research.

\section{Competing Interests Statement}

The authors declare that there are no competing or potential conflicts of interest.

\section{References}

Agbaraji, E. C., \& Ezeh, G. N. (September 2012).Food and Drug Counterfeiting in the Developing Nations; the Implications and Way-out. Academic Research International, 3(2), 24-33.

Akinyandenu, O. (2013). Counterfeit drugs in Nigeria: A threat to public health. African Journal of Pharmacy and Pharmacology, 7(36), 2571-2576. https://doi.org/10.5897/AJPP12.343

Akunyili, D. (2005). Counterfeit and Sub-standard Drugs, Nigeria's Experience: Implications, Challenges, Actions and Recommendations. A paper presented at a meeting for key interest groups on health organised by the World Bank in Washington D. C. 10th -11th March.

Akunyili, D. N. (2010). The War against Counterfeit Medicine: My Story. Ibadan: Safari Books Ltd.

Bamitale, K. D. S. (2013). The effects of fake and expired drugs on Health. Retrieved from http://www.oauife.edu.ng/wp-content/uploads/2013/05/fake-drug-andhealth-implications-by-bami tale.doc

Chandu, G. (2011). Detect Counterfeit Drugs Through Cloud Services Technology, System Evolved from HP's Pilot African Project. Retrieved from http://articles.economictimes.indiatimes.com/2011-09-29/news/30218200_1_counterfeitdrugs-life-saving-dr ugs-fake-medicines

Dike, O. N.,Onah, J. O., \& Onwuka, E. (2014). An Assessment of the Effects of Communication Network in Curbing Unethical Marketing Practices of Drug Firms in Nigeria. Management and Administrative Sciences Review, 3(2), 322-333.

Etzo, S., \& Collender, G. (2010). The mobile phone revolution in Africa: Rhetoric or reality? African Affairs, 109(437), 659-668. https://doi.org/10.1093/afraf/adq045

Foreman, J. (2014). Raman Spectroscopy used in the Identification of Counterfeit Pharmaceutical. Retrieved from http://www.centice.com/wpcontent/uploads/CounterfeitPharmaceuticalsand RamanSpectroscopy.pdf

IMPACT. (2013). Counterfeit drugs kill. Retrieved from www.who.int/impact

Iwokwagh, N. S. (2013). Assessment of New Media Use in the Fight against Counterfeit Medicines in Nigeria. International Conference on Communication, Media, Technology and Design, Famagusta - North Cyprus, pp.18-23.

Lambo, E. (2015). The World Bank and Malaria treatment.British Journal of Marketing Studies, 3(7), 30-49.

Osibo, O. O. (1998). Faking and counterfeiting of drugs. West African Journal of Pharmacy, 12(1), 53-57.

OurMed. (2015).Counterfeit Medications. Retrieved from http://www//ourmed.org/wiki/Counterfeit medications

Ukaoha, K. C., Dim, C. N., Odikayor-Ogbomo, F. I., \& Daodu, S. S. (2015). Towards A Mobile Drugs Authentication System for Nigerian Users. Computing, Information Systems, Development Informatics \& Allied Research Journal, 6(1), 35-40.

UNICEF. (2000). UNICEF's ACADA Model.InCommunication Handbook for Polio Eradication \& Routine EPI. New York: UNICEF Publication.

Wertheimer, A. I., \& Wang, P. G. (2012).Counterfeit Medicines; Policy, Economics and Countermeasures. Retrieved from http://arxiv.org/ftp/arxiv/papers/1211/1211.1242.pdf

WHO. (2013). What are Counterfeit medicines? Retrieved from www.who.int/medicines/services/counterfeit/faqs/03/en/

World Economic Forum. (2010). Advancing mhealth solutions. A paper presented at the mhealth summit, San Diego, California. 
Zeppa, S., \& Lewis, L. (2013). The FDA Releases Long-Awaited Final Guidance on Mobile Medical Applications. Retrieved from http://www.sheppardhealthlaw.com/2013/09/articles/other/the-fda-releaseslong-awaitedfinalguidance-on-mobile-medical-applications

\section{Copyrights}

Copyright for this article is retained by the author(s), with first publication rights granted to the journal.

This is an open-access article distributed under the terms and conditions of the Creative Commons Attribution license (http://creativecommons.org/licenses/by/4.0/). 